\title{
Efeito da aplicação de hCG ou GnRH sobre a concentração sérica de progesterona e eficiência reprodutiva em porcas
}

[Effect of injection of hCG or GnRH on progesterone serum concentration and reproductive efficiency of sows]

\author{
L.F.R. Carvalho ${ }^{1}$, J.M. Silva Filho ${ }^{1}$, I.J. Silva ${ }^{1}$, M.N. Bandeira ${ }^{1}$, M.P Morais ${ }^{2}$, J.R.M. Ruas ${ }^{3}$ \\ ${ }^{1}$ Escola de Veterinária da UFMG \\ Caixa Postal 567 \\ 30123-970 - Belo Horizonte, MG \\ ${ }^{2}$ DB Melhoramento Suíno \\ ${ }^{3}$ Empresa de Pesquisa Agropecuária de Minas Gerais
}

Recebido para publicação em 5 de dezembro de 2002

Recebido para publicação, após modificações, em 29 de setembro de 2003

*Autor para correspondência

E-mail: monteiro@vet.ufmg.br

\section{RESUMO}

Avaliou-se o efeito da aplicação de diferentes hormônios no quinto dia após a primeira inseminação sobre a concentração sérica de progesterona e sobre as características reprodutivas, em 103 porcas entre o terceirro e sexto parto. As matrizes foram divididas em: grupo-controle $(n=35)$, não tratado, grupo $\mathrm{GnRH}$ $(\mathrm{n}=34)$, animais submetidos à aplicação intramuscular (IM) de 50mcg de um análogo-GnRH no quinto dia após a primeira inseminação, e grupo hCG ( $n=34)$, animais submetidos à aplicação IM de 500UI de hCG no quinto dia após a primeira inseminação. A aplicação dos hormônios não influenciou as características reprodutivas taxa de parto, número total de nascidos, número de nascidos vivos e peso da leitegada $(\mathrm{P}>0,05)$. Cinco animais de cada grupo foram submetidos a coletas de sangue da veia cava nos dias 3, 5, 8, 12, 21 e 28 após a primeira inseminação para avaliação da concentração sérica de progesterona (ng/ml), utilizando a técnica de radioimunoensaio. Não houve diferença significativa quanto à concentração sérica de progesterona entre os grupos.

Palavras-chave: suínos, GnRH, hCG, progesterona, gestação

\begin{abstract}
Two different hormones were administered on the fifth day after the first insemination to evaluate their influence on serum progesterone concentrations and on reproductive efficiency, in multiparous sows between the third and the sixth parturition. The reproductive performance was evaluated in 103 sows distributed into three groups: 1-Control ( $n=35)$; 2-GnRH, $50 \mu \mathrm{g}$ of GnRH-analogue, administered IM on the fifth day after the first insemination ( $n=34)$; and 3-hCG, 500 IU of hCG administered IM in the fifth day after the first insemination $(n=34)$. No effect $(P>0.05)$ of hormone treatments on farrowing rate, litter size, live born and litter weight was observed. Five sows of each group were blood sampled on days $3,5,8,12,21,28$, after the first insemination, to evaluate serum progesterone concentrations ( $\mathrm{ng} / \mathrm{ml})$. Serum progesterone concentrations were not affected $(P>0.05)$ by hormone treatments.
\end{abstract}

Keywords: sow, GnRH, hCG, progesterone, pregnancy 


\section{INTRODUÇÃO}

O principal objetivo da eficiência reprodutiva dos suínos é o aumento do número de leitões nascidos por parto. Os dois principais componentes relacionados ao tamanho da leitegada são taxa de ovulação e mortalidade embrionária. van der Lende e Schoenmaker (1990), em extensa revisão sobre o assunto, ressaltaram que o aumento na taxa de ovulação não foi seguido por aumento significativo da leitegada e que alta taxa de ovulação é negativamente correlacionada com a sobrevivência embrionária.

No início da gestação o embrião necessita de secreções uterinas para sua sobrevivência e crescimento. Nessa fase são importantes as proteínas uterinas específicas secretadas em resposta à progesterona sangǘnea (Hughes, 1994). Menor concentração da progesterona circulante no período inicial da gestação pode resultar em maior mortalidade embrionária (Jindal et al., 1997).

Em algumas espécies domésticas têm sido utilizadas formas de modulação hormonal na tentativa de aumentar a concentração de progesterona plasmática no início da gestação, com o objetivo de melhorar o ambiente uterino e reduzir a mortalidade embrionária. Schmitt et al. (1996) confirmaram a presença de corpo lúteo acessório em vacas tratadas com hCG ou agonista de GnRH, no quinto dia do ciclo estral.

A indução de corpos lúteos acessórios poderia ser uma forma de elevar a concentração de progesterona plasmática e aumentar a sobrevivência embrionária em vacas (Wolfenson et al., 1994). Guthrie e Polge (1976), em experimento visando sincronização de cio em marrãs, induziram a formação de corpo lúteo acessório e também maior concentração de progesterona, com aplicações de gonadotrofina coriônica eqüina (eCG) no sétimo dia após o início do estro, seguida por aplicações de hCG no $10^{\circ}$ dia após o seu início. No mesmo experimento, utilizando diferentes protocolos após aplicações de eCG e hCG, respectivamente, nos dias 3 e 6, 11 e 14, 13 e 16, 15 e 18, também foram obtidos corpos lúteos acessórios, com menores concentrações de progesterona plasmática.

Em suínos, a aplicação de gonadotrofinas na fase lútea do ciclo estral leva à formação de corpos lúteos acessórios (Guthrie, Polge, 1976) e ao aumento da secreção de progesterona pelos corpos lúteos existentes (Wiesak, 1989). Portanto, a aplicação de gonadotrofinas no período inicial de gestação poderia, dessa forma, aumentar a secreção de progesterona sangüínea no início da gestação.

O objetivo deste experimento foi avaliar o efeito da administração de hCG ou buserelina (um análogo do $\mathrm{GnRH}$ ) no quinto dia após a terceira inseminação sobre a concentração sérica de progesterona até 28 dias de gestação e sobre o desempenho reprodutivo de porcas.

\section{MATERIAL E MÉTODOS}

Foram utilizadas 103 porcas híbridas, do terceiro ao sexto parto, provenientes da mesma semana de cobrição. As matrizes desmamaram seus leitões, em média, quando eles estavam com 19 dias de idade. A desmama ocorreu sempre às quintas-feiras pela manhã, quando as porcas, levadas em lotes para o galpão de gestação, foram distribuídas aleatoriamente entre os tratamentos e mantidas em gaiolas individuais. A rufiação foi feita pela manhã e à tarde utilizando-se um macho adulto de boa libido, colocado na frente das gaiolas, e pressionando-se o dorso das fêmeas. As inseminações foram realizadas 12 horas após o início do cio e repetidas 24 e 36 horas após, sempre na presença do cachaço. As doses inseminantes, preparadas em laboratório da própria granja, foram armazenadas por no máximo 48 horas.

As matrizes foram divididas em: grupo-controle (não tratado; n=35), grupo $\mathrm{GnRH}(\mathrm{n}=34)$, tratado com $50 \mathrm{mcg}$ de um análogo de GnRH (Gonadorelina. Cystorelin ${ }^{\circledR}$ Merial Saúde Animal), via IM no quinto dia após a primeira inseminação e grupo hCG $(\mathrm{n}=34)$, tratado com 500UI de hCG (Gonadotrofina Coriônica Humana. Vetecor® Serono Veterinária), via IM no quinto dia após a primeira inseminação. 
Para a avaliação da concentração sérica de progesterona foram utilizadas cinco fêmeas inseminadas de cada tratamento. Amostras de sangue foram coletadas no $3^{\circ}, 5^{\circ}, 8^{\circ}, 12^{\circ}, 21^{\circ}$ e $28^{\circ}$ dias após a primeira inseminação por punção da veia cava (Muirhead, Alexander, 1997), estocadas em tubos de ensaio de 10ml (suspensos sobre gelo em caixa de isopor por 10 minutos para formação de coágulo sangüíneo e retirada do soro) e congeladas à $-22^{\circ} \mathrm{C}$. A avaliação da concentração sérica de progesterona foi feita pela técnica de radioimunoensaio (RIA) de fase sólida, utilizando um conjunto comercial (Coat-a-Count ${ }^{\circledR}$ Progesterone KIT, DPC-Medlab) em contador de cintilação de radiação gama (Minigamma Gamma Counte ${ }^{\circledR}$, modelo LKB Wallac 1275), realizada no laboratório de Biofísica do Instituto de Ciências Biológicas da Universidade Federal de Minas Gerais.

Estudaram-se as variáveis relacionadas à condição corporal (peso, escore corporal e espessura de toucinho- mensuradas no início dos tratamentos e aos 30 e 110 dias de gestação) e ao desempenho reprodutivo (taxa de gestação, descarte, taxa de parto, nascidos totais, nascidos vivos, natimortos, mumificados e peso da leitegada ao nascer). Para mensuração da espessura de toucinho utilizou-se aparelho de ultrasom (SNK, Pig Scan, Sonda MB 4S) sobre o ponto $\mathrm{P}_{2}$ como preconizado por Roppa (1991). Para avaliação do escore corporal utilizou-se a classificação proposta por Chacon (1991).

As características produtivas peso e espessura de toucinho, as reprodutivas número total de nascidos, número de nascidos vivos e peso total da leitegada, e a concentração sérica de progesterona foram submetidas à análise de variância, e as diferenças entre médias aos testes Student e Student-NewmanKeuls (Sampaio, 1998). Para avaliação do efeito dos tratamentos sobre o escore corporal foi utilizado o teste Kruskal-Wallis (Sampaio, 1998). As médias foram comparadas pelos testes SNK e Kruskal-Wallis usando-se o Sistema de Análises Estatísticas 7.0 (Universidade..., 1997). As características reprodutivas taxa de parto, taxa de corrimento, taxa de gestação aos 30 dias de gestação, taxa de aborto e taxa de natimortos e mumificados foram avaliadas pelo teste do qui-quadrado (Sampaio, 1998).

\section{RESULTADOS E DISCUSSÃO}

As concentrações séricas de progesterona $(\overline{\mathrm{X}} \pm \mathrm{s})$ de fêmeas suínas gestantes segundo o dia de coleta são apresentadas na Fig. 1. Todas elas não retornaram ao cio após o $19^{\circ}$ dia depois da primeira inseminação e foram consideradas gestantes.

Uma matriz do grupo GnRH e outra do grupo hCG apresentaram problemas no aparelho locomotor após o $28^{\circ}$ dia de coleta e foram descartadas.

A administração de hCG ou do análogo de GnRH no quinto dia após a primeira inseminação não resultou em diferenças na concentração sérica de progesterona até o $28^{\circ}$ dia de gestação em relação ao grupocontrole. O pico de concentração sérica de progesterona ocorreu entre o $12^{\circ}$ e o $21^{\circ}$ dia de gestação, semelhante ao descrito na literatura (Archbong et al., 1987; Ashworth et al., 1994). Os valores encontrados foram numericamente superiores aos citados pela literatura provavelmente pelo fato deste trabalho ter utilizado matrizes pluríparas ao invés de marrãs no início da gestação, normalmente usadas nos experimentos citados. A regressão da variável dependente concentração sérica de progesterona (PROG) em relação ao dia de coleta (DIA) resultou na seguinte equação (Fig. 2): PROG= $10,565+8,47793$ (DIA)-0,49782(DIA) ${ }^{2}+0,0084638(\mathrm{DIA})^{3}, \mathrm{R}^{2}=0,68(\mathrm{P}<0,001)$.

$\mathrm{O}$ valor de $\mathrm{R}^{2}$ mostra ser o dia de coleta fator preponderante no resultado final da concentração sérica de progesterona, indicando distribuição homogênea dos dados, com o ápice da curva entre o $12^{\circ}$ e $21^{\circ}$ dia pós-inseminação.

Na literatura consultada não foram encontrados trabalhos que estudassem a modulação hormonal da secreção de progesterona utilizando gonadotrofinas no início da gestação em fêmeas pluríparas suínas. Os 
trabalhos consultados utilizaram marrãs como modelo durante o ciclo estral (Guthrie, Polge, 1976; Wiesak, 1989).

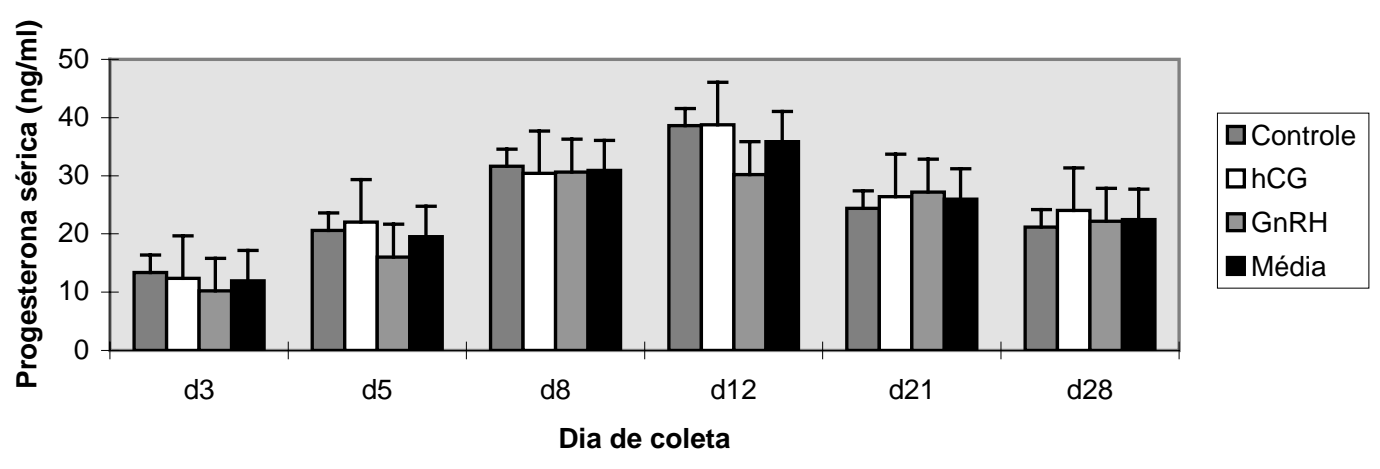

Figura 1. Concentração sérica de progesterona em matrizes suínas submetidas à administração de hCG ou análogo de GnRH no quinto dia após a primeira inseminação $(\mathrm{P}>0,05)$.

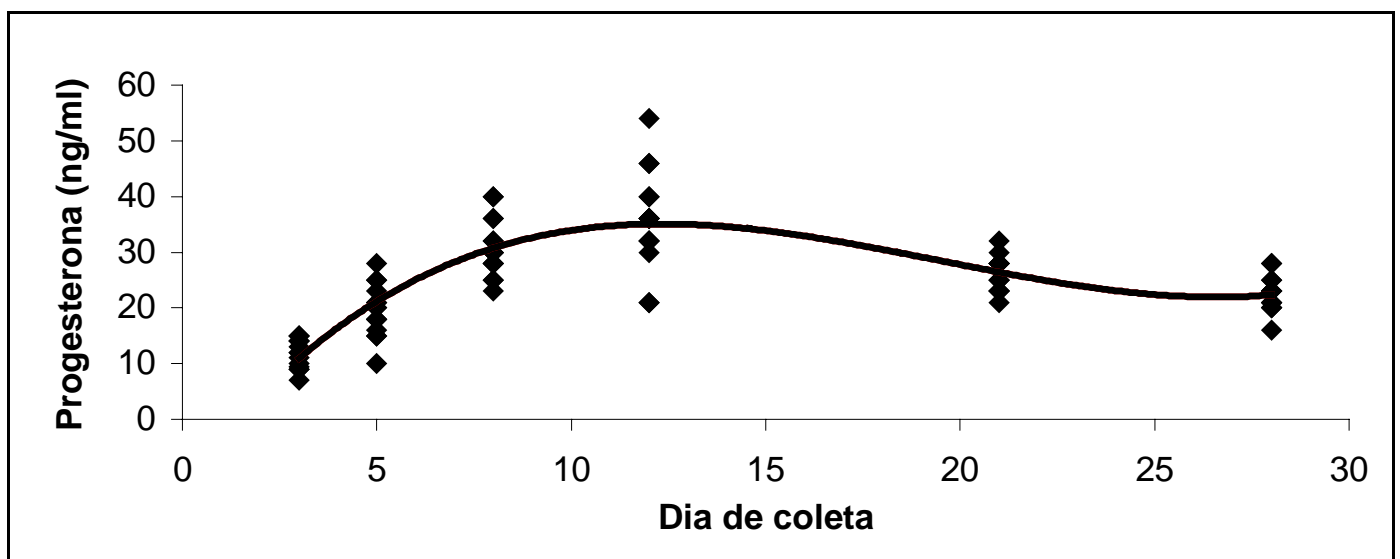

Figura 2. Concentração sérica de progesterona em função do dia de coleta em matrizes submetidas à administração de hCG ou análogo de GnRH no quinto dia após a primeira inseminação $(\mathrm{P}<0,0001)$.

Neste experimento possivelmente não houve formação de corpos lúteos acessórios ou maior produção individual de progesterona pelos corpos lúteos existentes, ao se considerar que a aplicação de gonadotrofinas não influenciou $(\mathrm{P}>0,05)$ a concentração sérica de progesterona. A aplicação de gonadotrofinas durante o ciclo estral de matrizes suínas leva à formação de corpos lúteos acessórios (Guthrie, Polge, 1976; Wiesak, 1989), com aumento da concentração sérica de progesterona (Guthrie, Polge, 1976; Wiesak, 1989). Uma única aplicação de hCG no $12^{\circ}$ dia do ciclo estral em suínos, além disso, ocasiona maior produção de progesterona pelos corpos lúteos in vitro (Wiesak,1989), provavelmente pela maior estimulação do corpo lúteo devido ao maior número de receptores de LH/hCG (Ziecik et al., 1980).

Os resultados podem ser atribuídos ao protocolo utilizado. A ausência de resultados positivos quanto ao possível aumento da progesterona das fêmeas tratadas com hCG ou com agonista do GnRH deve ser observada sobre dois ângulos. Inicialmente há que se considerar a ausência de uma onda folicular no início da gestação em suínos, com folículos capazes de responderem às gonadotrofinas aplicadas, de 
maturarem e ovularem, que aumentariam os níveis de progesterona (Foxcroft et al., 1994). Na ausência de folículos responsivos devem ser considerados os corpos lúteos ainda muito jovens e sem número razoável de receptores hCG/LH capazes de proporcionar resposta mensurável da concentração de progesterona. Nessa fase, a concentração de receptores é menor do que no período correspondente do ciclo estral, possivelmente em decorrência da regulação inibitória dos receptores pelo LH circulante, maior no período inicial de gestação que durante o ciclo estral. Além disso, tem-se observado que em torno do $12^{\circ}$ dia de gestação os receptores de LH estão com sua afinidade aumentada (Zieck et al., 1980).

Os resultados positivos com fêmeas em estro em experimentos anteriores foram obtidos após aplicação de eCG seguida da aplicação de hCG, no sétimo e $10^{\circ}$ dias do ciclo, respectivamente (Guthrie, Polge., 1976) ou após aplicação única de hCG no $12^{\circ}$ dia do ciclo estral (Guthrie, Rexroad Jr., 1981; Wiesak, 1989). Em ruminantes a aplicação de gonadotrofinas no quinto dia do ciclo estral ou pós-inseminação apresenta bons resultados quanto ao aumento da progesterona circulante (Schmitt et al., 1996) devido ao tipo de crescimento folicular que acontece em ondas, com presença de folículos com capacidade ovulatória no quinto dia do ciclo estral (Ginther et al., 1989). Em suínos, ao contrário do que acontece nos ruminantes, o recrutamento, seleção e dominância ocorrem somente a partir do $14-16^{\circ}$ dia do ciclo estral (Hunter et al., 1992; Foxcroft et al., 1994). No período anterior a essas fases, os folículos apresentam crescimento limitado e sofrem atresia sem um estímulo gonadotrófico adequado para seu crescimento (Foxcroft et al., 1994). No início da gestação o crescimento folicular está restrito aos folículos de até seis milímetros de diâmetro. Eles entram em atresia devido ao baixo estímulo gonadotrófico, porém, por volta do $12^{\circ}$ dia de gestação verifica-se a presença de folículos capazes de responder ao estímulo de LH (Wiesak et al., 1992). Assim, protocolos de aplicação de gonadotrofinas em suínos deveriam considerar a aplicação de duas doses, a primeira visando o desenvolvimento dos folículos pequenos, e a segunda a formação de corpos lúteos acessórios.

O desempenho reprodutivo das fêmeas é apresentado na Tab. 1. Não houve diferença entre tratamentos quanto às características avaliadas.

Tabela 1. Características reprodutivas de matrizes suínas de acordo com o tratamento

\begin{tabular}{lccccc}
\hline \multirow{2}{*}{ Característica } & & \multicolumn{4}{c}{ Tratamento } \\
\cline { 3 - 6 } & & Controle & GnRH & hCG & Total \\
\hline Taxa de gestação & $(\%)$ & 100 & 100 & 100 & 100 \\
aos 30 dias & $(\mathrm{n})$ & 5 & 5 & 5 & 15 \\
& $(\%)$ & 0 & 20,0 & 20,0 & 13,3 \\
Descarte & $(\mathrm{n})$ & 0 & 1 & 1 & 2 \\
& $(\%)$ & 100 & 80,0 & 80,0 & 86,7 \\
Taxa de parto & $(\mathrm{n})$ & 5 & 4 & 4 & 13 \\
& $(\overline{\mathrm{x}} \pm \mathrm{s})$ & $14,00 \pm 1,58$ & $12,00 \pm 2,71$ & $10,75 \pm 4,92$ & $12,38 \pm 3,27$ \\
Nascidos totais(n) & $(\overline{\mathrm{x}} \pm \mathrm{s})$ & $13,20 \pm 2,59$ & $11,00 \pm 2,70$ & $10,00 \pm 4,46$ & $11,53 \pm 3,43$ \\
Nascidos vivos(n) & $(\%)$ & 1,43 & 2,08 & 6,97 & 3,11 \\
Natimortos & $(\%)$ & 4,28 & 6,25 & 0 & 3,73 \\
Mumificados & $(\mathrm{x} \pm \mathrm{s})$ & $18,80 \pm 2,77$ & $16,88 \pm 3,28$ & $14 \pm 5,16$ & $16,73 \pm 4,02$ \\
Peso da leitegada $(\mathrm{kg})$ & $(\mathrm{n})$ & 5 & 4 & 4 & 13 \\
\hline
\end{tabular}

Os resultados podem ser considerados normais para a suinocultura atual segundo o proposto por Sesti e Sobestiansky (1998), com exceção do número de natimortos, com valores acima do proposto no tratamento hCG e do número de mumificados nos tratamentos controle e GnRH, apesar de não ter havido diferença estatística entre os tratamentos. Resultados semelhantes foram observados por Bandeira (1999) no mesmo rebanho, com valores maiores do que os propostos como ideais por Sesti e Sobestiansky (1998). Em matrizes suínas de alta fertilidade, como as utilizadas neste experimento, são esperados 


\section{Carvalho et al.}

maiores percentuais de natimortos e mumificados, como citado por Christianson (1992) e Bandeira (1999).

\section{CONCLUSÕES}

Não se observou efeito das gonadotrofinas sobre os níveis de progesterona circulante nem sobre a eficiência reprodutiva de fêmeas suínas pluríparas.

\section{REFERÊNCIAS BIBLIOGRÁFICAS}

ARCHIBONG, A.E.; ENGLAND, D.C.; STORMSHACK, F. Factors contributing to early embrionic mortality in gilts bred at first estrus. J. Anim. Sci., v.64, p.474-478, 1987.

ASHWORTH, C.J.; ROSS, A.W.; HALEY, C.S. Comparisions between peripheral progesterone concentrations in cyclic and pregnant landrace x large white and meishan gilts. Reprod. Fertil. Dev., v.6, p.777-782, 1994.

BANDEIRA, M.N. Fracionamento da alimentação diária na fase inicial de gestação e desempenho reprodutivo de fêmeas suínas. 1999. 85p. Dissertação (Mestrado). Escola de Veterinária, Universidade Federal de Minas Gerais, Belo Horizonte.

CHACON, H.L.A. Efeito da ocitocina e neostigmina, associadas ou não ao sulfato de sódio, sobre a natimortalidade na espécie suína. 1991. 62p. Dissertação (Mestrado). Escola de Veterinária, Universidade Federal de Minas Gerais, Belo Horizonte.

CHRISTIANSON, W.T. Stillbirths, mummies, abortions and early embrionic death. Vet. Clin. North. Am.: Food Anim. Pract., v.8, p.623-639, 1992.

FOXCROFT, G.R.; COSGROVE, J.R.; DING, J. et al. Reproductive function: current concepts. In: COLE, D.A.; WISEMAN, J.; VALEY, M.A. Principles of pig science. Nottingham: Nothingham University Press, 1994. p.225-252.

GINTHER, O.J.; KNOPF, L.; KASTELIC, J.P. Temporal associations among ovarian events in cattle during oestrous cycle with two or three follicular waves. J. Reprod. Fertil., v.87, p.223-230, 1989.

GUTHRIE, H.D.; POLGE, C. Control of oestrous and fertility in gilts with accessory corpora lutea by prostaglandin analogues, ICI 79.939 and ICI 80.996. J. Reprod. Fertil., v.48, p.427-430, 1976.

GUTHRIE, H.D.; REXROAD Jr., C.E. Endometrial prostaglandinf release In vitro and plasma 13,14-dihydro-15-ketoprostaglandin $\mathrm{F}_{2}$ alfa in pigs with luteolysis blocked by pregnancy, estradiol benzoate or human chorionicgonadotropin. $J$. Anim. Sci., v.52, p.330-339, 1981.

HUGHES, P. Feeding or breeding enhancing reproductive performance of pigs. Feed Mix., v.2, p.9-13 , 1994.

HUNTER, M.G.; BIGGS, C.; FAILLACE, L.S. et al. Current concepts of folliculogenesis in monovular and polyovular farm species. J. Reprod. Fertil. Suppl., v.45, p.21-38, 1992.

JINDAL, R.; COSGROVE, J.R.; FOXCROFT, G.R. Progesterone mediates nutritionally induced effects on embryonic survival in gilts. J. Anim. Sci., v.75, p.1063-1070, 1997

MUIRHEAD, M.R.; ALEXANDER, T.J.L. Reproduction: non infectious infertility. In: Managing pig health and the treatment of disease, 1997. Cap.5, p.163-164. 608p.

ROPPA, L.A. A nutriçao e a alimentação da fêmea reprodutoras. In: CONGRESSO BRASILEIRO DE REPRODUÇÃO ANIMAL, 9, 1991, Belo Horizonte. Anais... Belo Horizonte: CBRA, 1991. p.217-247.

SAMPAIO, I.B.M. Estatística aplicada à produção animal. Belo Horizonte: Fundação de Estudo e Pesquisa em Medicina Veterinária e Zootecnia, 1998. 221p.

SCHMITT, É.J.P.; DIAZ, T.; BARROS, C.M. et al. Differential responses of the luteal phase in cattle folowing ovulation of the first wave follicle with human corionic gonadotrophin or gonadotrophin-release hormone. J. Anim. Sci., v.74, p.10741083, 1996.

SESTI, L.A.C.; SOBESTIANSKY, J. Aspectos da produtividade. In: SOBESTIANSKY, J.; WENTZ, I.; SILVEIRA, P.R.S. et al. Suinocultura intensiva. Brasília: Serviço de Produção de Informação, 1998. 388p. Cap.4, p.65-90.

UNIVERSIDADE Federal de Viçosa-UFV- Sistema de Análises Estatísticas, versão 7.0. Viçosa, MG, 1997. 150p. 
Efeito da aplicação de hCG ou GnRH...

van der LENDE, T.; SCHOENMAKER, G.J.W. The relationship between rate and litter size before and after day 35 of pregnance in gilts and sows: an analyses of published data. Livest. Prod. Sci., v.26, p.217-229, 1990.

WIESAK, T. Effect of pregnancy, injection of oestradiol benzoate or hCG on steroid concentration and release by pig luteal cells. J. Reprod. Fertil., v.86,p.247-254, 1989.

WIESAK, T.; HUNTER, M.G.; FOXCROFT, G.R. Effect of prostaglandins on luteal function during early pregnancy in pigs. J. Reprod. Fertil., v.95, p.831-840, 1992.

WOLFENSON, D.; THATCHER, W.W.; SAVIO, J.D. et al. The effect of a GnRH analogue on the dinamics of follicular development and syncronization of estrus in lactating cows. Theriogenology, v.42, p.633-644, 1994.

ZIECIK, A.; SHAW, H.J.; FLINT, A.P.F. Luteal LH receptors during the oestrous cycle and early pregnancy in the pig. J. Reprod. Fertil., v.60, p.129-137, 1980. 